\title{
How pharmacy's adoption of social media can enhance patient outcomes
}

This article was published in the following Dove Press journal:

Integrated Pharmacy Research and Practice

9 July 2014

Number of times this article has been viewed

\section{Maria Bell \\ Jan Douglas \\ Christopher Cutts}

Centre for Pharmacy Postgraduate Education, Manchester Pharmacy School, University of Manchester, Manchester, UK
Correspondence: Christopher Cutts Centre for Pharmacy Postgraduate Education, Manchester Pharmacy School, University of Manchester, Oxford Rd,

Manchester, UK

Tel $+44 \quad$ I $6 \quad 17784000$

Fax +44 I6 I778 4030

Email christopher.cutts@manchester.ac.uk
Abstract: Social media is progressively being used for sharing health information and for networking among health professionals and patients; this is particularly evident among the younger age groups. There is great potential for pharmacy to engage in the utilization of such platforms to improve health outcomes, and this paper explores some of the areas where social media is already in use in pharmacy and potential areas where using social media could make a positive impact on the determinants of health. The literature around this subject is limited; nevertheless, the number of published studies has increased in recent years. This paper concentrates on the use and application of social media by pharmacy to improve health outcomes. The subject was explored in five main areas: provision of medicines information, safer use of medicines, medicines use in chronic disease, implementation of evidence-based medicine and guidelines, and finally clinical research. In each of these areas, there is an increase in uptake and use of social media platforms by pharmacists and other health care professionals to improve patient outcomes. A variety of the more popular social media platforms have been used by health care professionals and the relative merits of these are discussed within each of the subject areas and consideration given to their application in pharmacy practice. It is evident that the majority of social media users fall into the younger age bracket, which is understandable. However, the majority of patients living with long-term conditions typically fall into the older age bracket (over 65 years of age) and this should be taken into account when utilizing social media platforms to improve health outcomes.

Keywords: social media, pharmacy, outcomes, impact, health

\section{Background}

Social media is no longer considered "new" and its popularity and continued growth suggests that it is here to stay. It is a rapidly growing and developing arena. Once where phone calls, emails, and personal communication predominated, a large part of interpersonal communication is now facilitated by tweets, status posts, likes, and Snapchats. ${ }^{1}$ Eckler et $\mathrm{al}^{2}$ states that "the 'e-society' is pervasive, rapidly evolving and increasingly influencing the health care landscape". Another key factor in this e-revolution is access to social media via smart phones and tablets. It is very clear that pharmacy, as a profession and a service to customers and patients, needs to ensure it is aware of social media, understand the impact of this type of communication, and have a plan for engagement with and utilization of social media. This plan should further develop the care that pharmacists offer to patients, have a positive impact on health and health outcomes, and enhance the role of pharmacy in the health care team. 
Social media is commonly described as involving two key actions, ie, socialization and sharing, ${ }^{2}$ and the type of social media directly relates to these actions. Table 1 describes the types of social media, how they are defined, examples, and some of the available health-related social media sites. There are a plethora of social media sites and apps, and this only describes the most popular or well-known examples. It also appears that social media users are becoming quite fickle, with changes in use happening rapidly. Examples include the demise of $\mathrm{BeBo}$, the rebirth of $\mathrm{BeBo}$, and a shift to older users of Facebook. ${ }^{3}$

\section{Social media statistics}

There is an inexorable rise in uptake and use of social media, and the available statistics about use and users are astounding. While the majority of usage and engagement data are often provided on nonacademic websites (eg, http://www. thesocialskinny.com ${ }^{3}$ and http://www.blog.digitalinsights. $\left.\underline{\mathrm{in}}^{4}\right)$, they provide insight into the magnitude, changeability, and how social media is being used. Table 2 provides a summary of data on social media activity reported in 2013..$^{3-5}$

When relating these data to health care in general, there are some interesting points to consider. The desire for instant, mobile health care is growing with the increase in tablet and smart phone use, and online searching for health care advice and support is now common. A recent study found that over $90 \%$ of those aged $18-24$ years said they would trust health information they found on social media and that Facebook was the fourth most popular source for health information in the UK. ${ }^{6}$ Some authors have questioned this reliance on health care information from the Internet. ${ }^{7}$ Whatever the opinion of this health information in terms of its value and accuracy, it is expected that this trend of increasing use of the Internet and social media for health information will continue. ${ }^{6,8}$

\section{Use of social media and pharmacy}

There is limited information on pharmacists' use of social media. ${ }^{9}$ As this is developing quickly, the validity of published data has to be questioned. Shcherbakova and Shepherd ${ }^{10}$ surveyed pharmacists who had used social media in Texas. They found quite limited activity in terms of Facebook, Twitter, and other social media in a small-sized survey of community pharmacists, but almost all reported Internet access (97\%). The majority of pharmacists in this survey considered that social media could be used more to communicate with patients and become an established channel for communication. Cain et a ${ }^{11}$ looked at student use of Facebook in 2009, and found high use, indicating that future generations of pharmacy professionals will be social media users. In addition, some community

Table I Social media types, definitions, and examples

\begin{tabular}{|c|c|c|c|}
\hline Type & Definition & Example & $\begin{array}{l}\text { Health-related examples (not endorsed } \\
\text { or recommended) }\end{array}$ \\
\hline Blog & $\begin{array}{l}\text { Online journal or diary, where authors } \\
\text { share stories, opinions, or views }\end{array}$ & $\begin{array}{l}\text { http://www.blogger.com } \\
\text { http://www.tumblr.com } \\
\text { http://www.wordpress.org }\end{array}$ & $\begin{array}{l}\text { http://www.health.org.uk/blog } \\
\text { http://healthylivingblogs.com/location/uk/ } \\
\text { http://www.patient.co.uk/blogs } \\
\text { http://sharing.mayoclinic.org/ }\end{array}$ \\
\hline Microblog & $\begin{array}{l}\text { Similar to a blog, but posts are much } \\
\text { shorter and more contemporary }\end{array}$ & $\begin{array}{l}\frac{\text { Twitter.com }}{\text { Tumblr.com }} \\
\text { http://www.foursquare.com }\end{array}$ & $\begin{array}{l}\text { Almost all health organizations, bodies, and } \\
\text { leaders will have a Twitter account } \\
\text { http://www.moodmill.com } \\
\text { http://www.googlehealth.com }\end{array}$ \\
\hline Social networks & $\begin{array}{l}\text { Online communities that share } \\
\text { interests or activities, through profiles } \\
\text { which link together }\end{array}$ & $\begin{array}{l}\text { http://www.facebook.com } \\
\text { http://www.google plus } \\
\text { http://www.myspace.com }\end{array}$ & http://www.patientslikeme.com/ \\
\hline $\begin{array}{l}\text { Photo/video/file } \\
\text { sharing sites }\end{array}$ & $\begin{array}{l}\text { Website that allows sharing of } \\
\text { digital media }\end{array}$ & $\begin{array}{l}\text { http://www.youtube.com } \\
\text { http://www.flickr.com }\end{array}$ & $\begin{array}{l}\text { Many organizations have specific channels on } \\
\text { YouTube } \\
\text { http://www.youtube.com/user/PatientUK } \\
\text { http://www.youtube.com/user/kingsfund } \\
\text { http://www.youtube.com/user/NHSChoices }\end{array}$ \\
\hline $\begin{array}{l}\text { Instant messaging/ } \\
\text { contacts }\end{array}$ & $\begin{array}{l}\text { Website or app that allows easy } \\
\text { instant calls/messages/photographs and } \\
\text { location sharing to groups or individuals }\end{array}$ & $\begin{array}{l}\text { http://www.whatsapp.com } \\
\text { http://www.vibee.com } \\
\text { http://www.kik.com } \\
\text { http://www.snapchat.com }\end{array}$ & \\
\hline Wiki & $\begin{array}{l}\text { Website that allows user created and } \\
\text { developed web pages on their chosen } \\
\text { topic. Allows connectivity with a group }\end{array}$ & Wikipedia & $\begin{array}{l}\text { Many organizations will have Wikipedia pages } \\
\text { http://www.medikidz.com/medipedia/ }\end{array}$ \\
\hline
\end{tabular}


Table 2 Summary of data on social media activity reported in 2013

\begin{tabular}{ll}
\hline Example of social media & Data on activity \\
\hline Facebook & I.I5 billion users \\
& $23 \%$ of Facebook users check their \\
& accounts more than five times a day \\
& $75 \%$ of possible engagement with a post \\
& gets it in the first 5 hours \\
& $25 \%$ of users do not use privacy settings \\
& Over 500 million users with 288 million \\
active monthly \\
Twitter & $60 \%$ of users access it from mobile devices \\
& 400 million tweets per day \\
& Fastest growing age demographic is aged \\
& $55-64$ years \\
& Over 500 million users in the platform and \\
& $67 \%$ male \\
Google Plus & $60 \%$ users log in everyday \\
& 240 million users with I.5 million groups \\
& 3 million businesses have pages \\
& $50 \%$ of users have a degree \\
& 700 YouTube video links shared on \\
Linkedln & Twitter every minute \\
& 500 years' worth of YouTube videos \\
YouTube & watched on Facebook every day
\end{tabular}

Notes: Copyright @ 2013. Digital Insights. Reproduced from Digital Insights. Social media facts, figures and statistics 2013 . Available from: http://blog.digitalinsights.in/ social-media-facts-and-statistics-2013/0560387.html. ${ }^{4}$

pharmacy chains have started to use social media to promote products and services, with one chain being reported to have one million Twitter followers. ${ }^{1}$

Considering that many patients are social media users and the e-society is growing, it appears that the key question of how pharmacists can use social media to improve their patient care, practice, and health outcomes is an important one and leads us to consider what we know already. This review aims to present an overview of the published literature on how pharmacy's adoption of social media can or potentially can have an impact on patient outcomes.

\section{Search strategy}

A structured search was performed using the PubMed, Embase, and Google Scholar search engines. English language articles were identified up to December 2013. The search terms used were "social media", "social networking", "forums", "Twitter", "Facebook", "blogs", and "YouTube" in conjunction with "pharmacy", "pharmacist", and "outcome" or "impact". After some initial review of the findings and considering the very limited availability of the literature with regard to pharmacy, this review was then extended to include relevant papers and reviews which related to "health" or other "health care professionals" and could be translated to pharmacy practice. A systematic review was not undertaken.

\section{Results and discussion}

The literature review yielded a very limited number of papers directly related to pharmacy. Most of the pharmacy-related papers explored the impact and role of social media in education institutions and on professionalism. These papers have not been included in this review.

Broad themes (shown in Table 3) were identified where pharmacy could use social media to improve health outcomes. The results and discussion have been structured under these specific subheadings. It is clear that there are very limited high quality data or well-structured studies looking at social media and impact on health. This is probably due to the difficulty in designing studies that could clearly determine the unique impact of social media, coupled with the relative newness of social media and the rapidly changing social media environment.

\section{Impact on provision of health information, delivery of public health interventions, and enhanced patient engagement}

The most prolific use of social media in health care at present appears to be the provision of timely information to patients for the delivery of public health interventions. This is one area with the most developed literature relating to the impact of social media on health. There has been a range of reviews and studies focused on this area ${ }^{8,12-15}$ Moorhead et $\mathrm{al}^{13}$ undertook a systematic review of the uses, benefits, and limitations of social media for health communication. They concluded that social media brings a new dimension to communicating health information to patients, the public, and even health professionals, and this could include moving from communication to interaction, ie, patients being able to discuss their condition and their medication with the pharmacy team, rather than merely a one-way transfer of information. Concerns were raised about the quality and reliability of the data posted on social networking sites, together with patient privacy considerations; for example, there may be some

Table 3 Summary of proposed areas where social media could be used by pharmacy to improve health outcomes

\footnotetext{
Impact on provision of health information, delivery of public health interventions, and enhanced patient engagement

Impact on safer medicine use

Impact on management of chronic disease

Impact on dissemination and implementation of evidence-based medicine and guidelines

Impact on clinical research
} 
personal issues that patients are not willing to discuss openly and some aspects of their condition that they are.

Health care interventions via the Internet have recently shown promise in reaching patient groups that are traditionally difficult to recruit into programs, such as smoking cessation and substance misuse, ${ }^{16,17}$ and recent studies have demonstrated how the use of various social media can improve recruitment and retention in these programs. A study by Heffner et al ${ }^{18}$ utilized Facebook, Twitter, and Google AdWords in addition to the more traditional methods of recruitment (word of mouth and standard media) to recruit patients into an online smoking cessation program. Their findings suggest that there was no statistically significant difference in the demographics of patients recruited via social media versus traditional media, and the outcome did not vary in terms of smoking abstinence, suggesting that social media may be a useful additional tool in recruiting patients. The Haringey Man MOT scheme ${ }^{19}$ is an interesting use of social media directed toward health improvement in men, and is a good example of targeting hard to reach populations, given that it is well known that men are not always proactive in seeking health care advice. Through this service, men can "chat" directly with a health care professional about any problem via computer, tablet, or smart phone. This pioneering new project is still in the early stages of development; the project team plan to develop the service further through improving disease prevention, enabling early intervention, and providing local signposting.

Social media have been used to promote public health messages, such as sexual health interventions, as shown in a systematic review by Guse et $\mathrm{al}^{20}$ who examined eleven studies in total from a variety of countries. The interventions carried out included reminders to take antiviral medication in human immunodeficiency virus-positive young people, encouragement to use condoms, and advising adolescents to remove sexual references from their personal social networking site profiles. An interesting point to note for health care professionals is that several studies specifically reported that participants found online or digital intervention to be positive, with participants in one study preferring the online delivery method to that of a face-to-face session ${ }^{21}$ and those receiving mobile phone reminders stating that they found them "helpful and unobtrusive". ${ }^{22}$ Guse et $\mathrm{al}^{20}$ claim that there is tremendous potential in the fields of medicine and health to reach young populations, but suggest that more research is required to address the potential inequalities with regard to access to digital equipment in the lower socioeconomic groups.
Other studies have shown how periodic electronic prompts and reminders about healthy living and behaviors have been effective, often when combined with contact with health care staff. ${ }^{23}$ Another study showed encouraging replies from health care professionals and improved engagement from the patient. ${ }^{24}$ Other examples have included reminders for scheduling immunizations, recall of medicines, and reminders regarding medication reviews. ${ }^{2,8}$ Other people have proposed, with little retrospective evidence, the potential value of social media in public emergencies and crisis management, and how pharmacists could utilize the media in these situations. ${ }^{25}$

In a systematic review of the use of social networking sites for promotion of sexual health, Gold et $\mathrm{al}^{26}$ found that Facebook was the most commonly used (used for $71 \%$ of all health promotion activities identified), followed by MySpace and Twitter. These authors concluded that social networking sites have been used mainly in developed countries, including the USA and UK, to promote health-related information to young people, but note that the vast majority of health promotion projects remain unreported in the literature.

The role of social media in assisting patients with adherence to weight loss programs has been studied; these have used a variety of social media, including forums, ${ }^{27} \mathrm{Twitter},{ }^{28}$ and digital assistants. ${ }^{29}$ Weight loss results have been equivocal, and in many examples, the social media platforms have been used for peer support by the participants rather than provided by a health care professional. However, there is the potential for pharmacy to utilize social media to improve weight loss outcomes and this is worth further investigation.

Social media may offer promise in supporting patients who find it difficult to engage in traditional face-to-face peer support groups, such as those with mental health disorders. Morgan et $\mathrm{a}^{30}$ undertook recruitment to an online intervention for prevention of depression and utilized Facebook and Google advertising among other methods; their study website page received 94,808 visits, with 1,326 actively enrolling in the full program, demonstrating the volume of patients who can be reached for recruitment and interventions with using social media. In a study of 74 secondary school students, ${ }^{31}$ over half of the participants experienced a need for mental health support, with 53\% turning to the Internet. This study suggests that online social networking sites may be a method via which to offer vulnerable, isolated patients both professional and peer support.

Direct online health professional services are emerging whereby the patient can request a diagnosis, ${ }^{32}$ and in some cases diagnosis and treatment, ${ }^{33}$ via the Internet. These provide timely diagnosis and treatment for clear-cut illnesses, 
and are positive examples of how the Internet can be used by health care professionals to improve patient outcomes through timely diagnosis and early treatment, or if necessary, onward referral.

Social media has been utilized by patients to share information about their condition and offer advice on coping with chronic, debilitating disease via blogs and Twitter accounts. Currently much of these are initiated and supported by organizations such as Mind ${ }^{34}$ (London, UK), and the Arthritic Association ${ }^{35}$ (Eastbourne, UK); however, analyzing these communications can also offer health care professionals an insight into these conditions. Song et $\mathrm{al}^{36}$ demonstrate how videos and digital narratives were used to support and inspire a group of pediatric cancer survivors, encouraging them to discuss their long-term concerns, and in addition providing a valuable insight into the patient's psychological needs following treatment. http://www.epatientdave.com ${ }^{37}$ is the website and blog of a cancer survivor who shared his cancer journey in order to empower other patients to engage with health care options for treatment of their disease. The information provided on the ePatient Dave website enables patients to participate in decisions made about their health management to improve outcomes. There is potential for pharmacists to adopt a participatory approach such as this in their care of patients.

The opportunity for pharmacy to use social media in order to impact positively on the provision of health information for delivery of public health interventions and enhanced patient engagement seems robust and viable, but evidence is limited. Pharmacy-based interventions will need to be created before they can be evaluated. However, this model for recruiting patients appears to translate to the pharmacy arena, where social media interventions, reminders, and support could demonstrate similar success.

\section{Impact on safer use of medicines}

Social media is widely used by health care professionals and patients to obtain drug safety information, with ever increasing use being made of Wikipedia and other sources. ${ }^{6}$ However, usage by patient segments with the highest degree of health care utilization (ie, those aged over 65 years and those with multiple chronic conditions) lags behind that of the general population. Whilst the accuracy of drug information from nonregulated sites can be good, there is concern regarding the validity of data from social media sources. In addition, it is often incomplete and poorly cross-referenced. ${ }^{38}$ This is something that pharmacists should be aware of and take into account when providing drug safety information to patients.

Adverse event reporting via recognized channels, such as health care professionals and pharmaceutical companies, is strictly regulated with a clear legal framework and guidance. ${ }^{39}$ However, there is no requirement for companies to screen Internet or digital media not under their management or responsibility for potential reports of suspected adverse drug reactions. Although websites such as Healthtalk online ${ }^{40}$ and MediGuard ${ }^{41}$ can provide a useful forum for patients to discuss their conditions and medicines, including side effects, there is no guarantee that their experiences will be captured and used to augment drug safety via regulatory pharmacovigilance routes. Pharmacists should therefore encourage patients to report any adverse events via appropriate channels and not to rely on social media alone as a means of discussing such events.

There is significant potential to capture adverse event reports from social media sites. ${ }^{42,43}$ A study of a Facebook group set up to capture drug adverse events showed that this approach is feasible, and several of the events were considered to be drug-related. ${ }^{44}$ However, regulating these channels would require careful consideration and significant resources. In addition, natural biases of age, social class, education, and language, together with issues of confidentiality, misleading reports, and assigning causality, make capturing accurate data via social media hugely challenging.

In summary, there is great potential for pharmacists to engage with social media in novel ways to encourage patients to adhere with their medicine regimens by sharing information with patients at relevant times in a tailored way for the management of their disease.

\section{Impact on management of chronic disease}

Clearly, pharmacy would have a strong interest in how social media could improve the effectiveness and safety of medicines use. It is thought that up to $50 \%$ of all medicines prescribed are not taken as recommended. ${ }^{45}$ Adherence to medication ${ }^{46}$ is critical to the success of treatment for long-term conditions, and ultimately to the health-related outcomes and quality of life for the patient.

Merolli et al ${ }^{47}$ reviewed the literature on health outcomes and related effects of social media in management of chronic disease. They found very little evidence, but what existed indicated a positive impact on health status, social interaction, disease-specific knowledge, and psychosocial well-being, with no indication of adverse events. More evidence related to 
psychosocial aspects of the disease than to physical benefits. Most evidence related to the more established social media channels, such as discussion groups, online groups, and message boards.

Merolli et $\mathrm{al}^{47}$ also took an interest in "how" "use of social media may influence outcomes. The literature shows that social media affords patients more control over how they present and assert themselves. It also provides flexibility in regard to timing and location of communication about their health, which may challenge traditional health care delivery models.

Patients with long-term conditions use social media widely; however, this is mostly to help them better understand their chronic condition ${ }^{47}$ and for support and informationsharing. For patients with long-term conditions, most patient care/support ${ }^{47}$ takes place outside of visits to health care providers; ongoing support from a pharmacy via a social media platform could be fundamental to the patient to assist with medicines adherence.

Several papers have discussed the e-coach model using nurses. ${ }^{48,49}$ These engaged groups or specific patients with a nurse to offer support, monitoring, and information. Patients reported positive experiences in these studies. Models could be devised using a pharmacist e-coach focused around medicines. There are no published data looking at these types of models.

Cotter et $\mathrm{al}^{50}$ reviewed the effect of Internet interventions on lifestyle modifications and physical parameters, eg, glycated hemoglobin levels, in people with type 2 diabetes. This review revealed some evidence for improvement in physical determinants of disease. However, the data were variable; for some studies, there was a correlation between use of Internet intervention and improved glycated hemoglobin and/or healthy behaviors, but for other studies there was no correlation. In summary, there appears to be a clear opportunity for pharmacy to engage in chronic disease management programs that use social media to support patients, but once again, the literature supporting this is limited.

\section{Impact on dissemination and implementation of evidence-based medicine and guidelines}

With the permeation of social media into all aspects of life, it is reasonable to assume that it could be used to have an impact on dissemination and implementation of evidence-based medicine and guidelines. There is no literature directly exploring the role of pharmacy in this area, but associated literature can be explored and translated to pharmacy practice.
Scanfield et al $^{51}$ reviewed the Twitter status updates mentioning antibiotics. They showed that there was a wide discussion about antibiotic use and prescribing on Twitter, with some being accurate and some being inappropriate. This paper did not come to any conclusion on the impact of social media on use of antibiotics and, not surprisingly, recommended further research on how social media could promote positive behavior change and disseminate valid information. Allen et $\mathrm{al}^{48}$ looked at how social media could increase the dissemination of original articles on clinical pain services and concluded that social media increased the number of people who view or download original articles, but that this did not mean that the guidelines had been translated to practice. Also, enhancing education and learning could be another aspect of how social media could improve implementation of evidencebased use of medicines. ${ }^{52,53}$ Social media has been proposed to improve collegiality in the learning environment. ${ }^{54}$

While none of these data are particularly robust to demonstrate impact, there appears to be an obvious opportunity for pharmacy to use social media to promote evidence-based medicine and implementation of guidelines.

\section{Impact on clinical research}

Patients interested in taking part in clinical research trials have been able for some time to access trials information from a range of Internet sources, including government databases (eg, UK Clinical Trials Gateway) ${ }^{55}$ and proprietary sites (eg, Clinical connection). ${ }^{56}$ The broader application of social media in clinical trials has also been successful in enhancing patient recruitment and retention across a number of therapy areas. ${ }^{57}$ The rapid expansion of health-related social networks has resulted in the growth of crowd-sourced health research studies, including those organized by participants, ${ }^{58}$ with research from websites such as Patients like me $\mathrm{m}^{59}$ being published in a range of peer-reviewed journals.

Whilst social media provides significant opportunities to enhance clinical research, it also brings a number of challenges. Concerns over patient demographic bias are based on the known disparities between various groups relating to Internet access and use, particularly with respect to patient age. This was borne out in a smoking cessation study which showed a bias toward younger patients recruited via social media compared with more traditional recruitment methods, ${ }^{60}$ although other demographic parameters and smoking characteristics were evenly matched. Other concerns have been raised regarding the potential bias that could be introduced as a result of clinical trials participants posting material on social media sites and health forums. ${ }^{61}$ 


\section{Potential challenges for pharmacy and using social media}

The literature provides some insight into the challenges pharmacy would face if it widely adopted social media as a channel for working and caring for patients and the public. The first challenge would be how pharmacists would know that social media is likely to be effective in the area they choose, such as public health or management of long-term conditions. This review has shown the literature is still very limited; further, how would pharmacists track the fickle nature of social media trends and would they need to tailor their applications to specific demographics?

There are a few other challenges on the operational aspects of using social media. Generally, social media is not private and it is difficult to manage engagement; it is also poor at tailoring of information to specific patients due to the population approach. Pharmacy professionals would need to consider alternatives if patients could not manage or refused to access information via the chosen social media channel. Patient consent to using social media could be problematic too, if much of the contact is virtual.

Another concern regarding the use of social networking sites and related media is the accuracy and clinical appropriateness of the information found online; this may lead patients to make uninformed and dangerous decisions regarding their health, including self-medicating and nonadherence ${ }^{62}$ Health care professionals are increasingly aware of the impact of the Internet and potentially unreliable sources of information, and pharmacy can play a key role in the promotion of evidence-based information to patients.

The final issue relates to pharmacists themselves. The activity data show wide variation in use of social media, which is particularly linked to the age of pharmacists. Older pharmacy professionals may need significant training and experience if pharmacy was to fully embrace social media as part of its care of patients. Much has been written about professional standards and use of social media by professionals. Pharmacists will need to clearly divide their professional and private use of social media. It would be expected that regulators will provide further guidance as social media permeates health care.

\section{Conclusion}

Social media is currently being utilized across a wide variety of platforms and by numerous health care disciplines to increase access and engagement with patients, and to date, the limited literature available shows promising results. As government recognizes the key role that pharmacy can play in improving the health of nations, we need to embrace this new opportunity as a novel and positive change in the way we interact with our patients. However, as our health care system becomes increasingly outcome-driven, it would seem sensible to approach the use of social media with measurable outcomes firmly at the forefront of our planning. Interventions need to be carefully planned to protect patient privacy, to minimize bias toward certain age groups and socioeconomic class, and ultimately be measurable. By contributing to the current evidence base, the pharmacy profession can demonstrate their own worth and the place of social media in achieving better outcomes for patients.

\section{Disclosure}

The authors report no conflicts of interest in this work.

\section{References}

1. O'Hara B, Fox BI, Donahue B. Social media in pharmacy: heeding its call, leveraging its power. J Am Pharm Assoc. 2013;53:561-565.

2. Eckler PE, Worsowicz MD, Rayburn JW. Social media and health care: an overview. PM R. 2010;2:1046-1050.

3. The Social Skinny. 103 crazy social media statistics to kick off 2014. Available from: http://thesocialskinny.com/103-crazy-social-mediastatistics-to-kick-off-2014/. Accessed March 6, 2014.

4. Digital Insights. Social media facts, figures and statistics 2013. Available from: http://blog.digitalinsights.in/social-media-facts-and-statistics2013/0560387.html. Accessed March 6, 2014

5. jeffbullas.com. The 10 big social media marketing trends in 2014 Available from: http://www.jeffbullas.com/2014/01/07/the-10-bigsocial-media-marketing-trends-in-2014/. Accessed March 6, 2014.

6. IMS Institute for Health Care Informatics. Engaging patients through social media. Report January 2014. Available from: http://www imshealth.com/portal/site/imshealth/menuitem.c76283e8bf81e98f53c $753 \mathrm{c} 71 \mathrm{ad} 8 \mathrm{c} 22 \mathrm{a} /$ ?vgnextoid=ebc072cc270b3410VgnVCM100000761 92ca2RCRD. Accessed March 6, 2014.

7. Antheunis ML, Tates K, Nieboor TE. Patients' and health professionals' use of social media in health care: motives, barriers and expectations. Patient Educ Couns. 2013;92:426-431.

8. Bennett GG, Glasgow RE. The delivery of public health interventions via the Internet: actualizing their potential. Ann Rev Public Health. 2009;30:273-292.

9. Alkhateeb FM, Clauson KA, Latif DA. Pharmacist use of social media Int J Pharm Pract. 2011;19:140-142.

10. Shcherbakova N, Shepherd M. Community pharmacists, Internet and social media: an empirical investigation. Res Social Adm Pharm. Epub 2013 December 4.

11. Cain J, Scott DR, Akers P. Pharmacy students' Facebook activity and opinions regarding accountability and e-professionalism. Am J Pharm Educ. 2009;73:104.

12. Chou WS, Hunt YM, Beckford EB, Moser RP, Hesse BW. Social media use in the United States: implications for health communication. J Med Internet Res. 2009;11:e48.

13. Moorhead SA, Hazlett DE, Harrison L, Carroll JK, Irwin A, Hoving C. A new dimension of health care: systematic review of the uses, benefits, and limitations of social media for health communication. J Med Internet Res. 2013;15:e85.

14. Thackeray R, Crookston BT, West JH. Correlates of health related social media use among adults. J Med Internet Res. 2013;15:e21.

15. Donelle L, Booth RG. Health tweets: an exploration of health promotion on Twitter. Online J Issues Nurs. 2012;17:4. 
16. Berwick BM, Trusler K, Barkham M, Hill AJ, Cahill J, Mulhern B. The effectiveness of web-based interventions designed to decrease alcohol consumption. Prev Med. 2008;47:17-26.

17. Brendryen H, Drozd F, Kraft P. A digital smoking cessation programme delivered through Internet and cell phone without nicotine replacement. Randomized control trial. J Med Internet Res. 2008;10:e51.

18. Heffner J, Wyszynski C, Comstock B, Mercer L, Bricker J. Overcoming recruitment challenges of web-based interventions for tobacco use: the case of web-based acceptance and commitment therapy for smoking cessation. Addict Behav. 2013;38:2473-2476.

19. Men's Health Forum. Available from: http://www.menshealthforum. org.uk/Haringey. Accessed April 2, 2014.

20. Guse K, Levine D, Martins S, et al. Interventions using new digital media to improve adolescent sexual health: a systematic review. J Adolesc Health. 2012;51:535-543.

21. MarschLA, Grabinski MJ, BickelWK. Computer assisted HIV prevention for youth with substance use disorders. Subst Use Misuse. 2011;46: 46-56.

22. Puccio JA, Belzer M, Olson J. The use of cell phone reminder calls for assisting HIV-infected adolescents and young adults to adhere to highly active anti-retroviral therapy: a pilot study. AIDS Patient Care STDS. 2006;20:438-444.

23. Fry JP, Neff RA. Periodic prompts and reminders in health promotion and health behavior interventions: systematic review. J Med Internet Res. 2009;11:e16.

24. Korman KP, Shrewsbury VA, Chou AC, et al. Electronic therapeutic contact for adolescent weight management: the Loozit ${ }^{\circledR}$ study. Telemed $J$ E Health. 2010;16:678-685.

25. Merchant RM, Elmer S, Lurie N. Integrating social media into emergency-preparedness efforts. N Engl J Med. 2011;365:289-291.

26. Gold J, Pedrana AE, Sacks-Davis R, et al. A systematic examination of the use of online social networking sites for sexual health promotion. BMC Public Health. 2011;11:583.

27. Chang T, Chopra V, Zhang C, Woolford SJ. The role of social media in online weight management: systematic review. J Med Internet Res. 2013; 15:e262.

28. Turner-McGrievy GM, Tate DF. Weight loss social support in 140 characters or less: use of an online social network in a remotely delivered weight loss intervention. Transl Behav Med. 2013;3: 287-294.

29. Burke LE, Styn MA, Sereika SM, et al. Using mHealth technology to enhance self-monitoring for weight loss: a randomized trial. Am J Prev Med. 2012;43:20-26.

30. Morgan AJ, Jorm AF, Mackinnon AJ. Internet-based recruitment to a depression prevention intervention: lessons from the Mood Memos study. J Med Internet Res. 2013;15:e31.

31. O'Dea B, Campbell A. Healthy connections: online social networks and their potential for peer support. Stud Health Technol Inform. 2011;168:133-140.

32. The Online Doctor. Available from: http://www.the-online-doctor.com. Accessed April 2, 2014.

33. White Pharmacy. Online consultations. Available from: http://www. whitepharmacy.co.uk/online-consultation\#.Ux896T877Sg. Accessed April 2, 2014.

34. mind.org.uk [homepage on the Internet]. London, UK: Mind; 2014. Available from: http://www.mind.org.uk/. Accessed March 6, 2014.

35. arthriticassociation.org.uk [homepage on the Internet]. Eastbourne, UK: The Arthritic Association; 2014. Available from: https://www. arthriticassociation.org.uk/. Accessed March 6, 2014.

36. Song H, Nam Y, Gould J, et al. Cancer survival identity shared in a social media intervention. J Pediatr Oncol Nurs. 2012;29:80-91.

37. E-patient Dave. Available from: http://www.epatientdave.com. Accessed April 2, 2014.

38. Lavsa SM, Corman SL, Culley CM, Pummer TL. Reliability of Wikipedia as a medication information source for pharmacy students. Currents in Pharmacy Teaching and Learning. 2011;3: 154-158.
39. Association of the British Pharmaceutical Industry. Guidance notes on the management of adverse events and product complaints from digital media. Dated April 8, 2013. Available from http://www.abpi.org.uk/ our-work/library/guidelines/Pages/safety-data-websites.aspx. Accessed March 6, 2014.

40. Healthtalk online. Available from: http://healthtalkonline.org/. Accessed March 6, 2014.

41. MediGuard. Available from: https://uk.mediguard.org/. Accessed March 6, 2014.

42. Banerjee AK, Ingate S. Web-based patient-reported outcomes in drug safety and risk management: challenges and opportunities? Drug Saf. 2012;35:437-446

43. Edwards R, Lindquist M. Social media and networks in pharmacovigilance. Boon or bane? Drug Saf. 2011;34:267-271.

44. Knezevic MZ. Using Facebook to increase spontaneous reporting of adverse drug reactions. Drug Saf. 2011;34:351-352.

45. World Health Organisation. Medicines: rational use of medicines. Available from: http://www.who.int/mediacentre/factsheets/fs338/en/. Accessed March 6, 2014.

46. National Institute for Health and Care Excellence. Clinical guideline 76. Medicines adherence: involving patients in decisions about prescribed medicines and supporting adherence. Available from: http://guidance. nice.org.uk/CG76. Accessed March 6, 2014.

47. Merolli M, Gray K, Martin-Sanchez F. Health outcomes and related effects of using social media in chronic disease management: a literature review and analysis of affordances. J Biomed Inform. 2013;46: 957-969.

48. Allen M, Lezzoni LI, Huang A, Huang L, Leveille SG. Improving patient-clinician communication about chronic conditions: description of an Internet-based nurse E-coach intervention. Nurs Res. 2008;57:107-112.

49. Baptist AP, Thompson M, Grossman KS, Mohammed L, Sy A, Sanders GM. Social media, text messaging, and email-preferences of asthma patients between 12 and 40 years old. J Asthma. 2011;48: 824-830.

50. Cotter AP, Durant N, Agne AA, Cherrington AL. Internet interventions to support lifestyle modification for diabetes management: a systematic review of the evidence. J Diabetes Complications. 2014;28: $243-251$.

51. Scanfield D, Scanfield V, Larson EL. Dissemination of health information through social networks: Twitter and antibiotics. Am J Infect Control. 2010;38:182-188.

52. Prasad B. Social media, health care, and social networking. Gastrointest Endosc. 2013;77:492-495.

53. Von Muhlen M, Ohno-Machado L. Reviewing social media use by clinicians. J Am Med Inform Assoc. 2012;19:777-781.

54. Cain J, Romanelli F, Fox B. Pharmacy, social media and health: opportunity for impact. J Am Pharm Assoc. 2010;50:745-751.

55. UK Clinical Trials Gateway. Available from: http://www.ukctg.nihr. ac.uk/default.aspx. Accessed February 4, 2014.

56. Clinical connection. Available from: http://www.clinicalconnection. com/. Accessed March 6, 2014.

57. Allison M. Can web 2.0 reboot clinical trials? Nat Biotechnol. 2009;27: 895-902.

58. Swan M. Crowd sourced health research studies: an important emerging complement to clinical trials in the public health research ecosystem. J Med Internet Res. 2012;14:e46.

59. Patients like me. Available from: http://www.patientslikeme.com/. Accessed February 4, 2014.

60. Frandsen M, Walters J, Ferguson S. Exploring the viability of using online social media advertising as a recruitment method for smoking cessation clinical trials. Nicotine Tob Res. 2014;16:247-251.

61. Glickman SW, Galhenage S, McNair L, et al. The potential influence of internet-based social networking on the conduct of clinical research studies. J Empir Res Hum Res Ethics. 2012;7:71-80.

62. Young S. Recommendations for using online social networking technologies to reduce inaccurate online health information. Online $J$ Health Allied Sci. 2011;10(2 Pt 2):2. 
Integrated Pharmacy Research and Practice

Dovepress

\section{Publish your work in this journal}

Integrated Pharmacy Research and Practice is an international, peer-reviewed, open access, online journal, publishing original research, reports, reviews and commentaries on all areas of academic and professional pharmacy practice. This journal aims to represent the academic output of pharmacists and pharmacy practice with particular focus on integrated care. All papers are carefully peer reviewed

Submit your manuscript here: http://www.dovepress.com/integrated-pharmacy-research-and-practice-journal to ensure the highest standards as well as ensuring that we are informing and stimulating pharmaceutical professionals. The manuscript management system is completely online and includes a very quick and fair peer-review system, which is all easy to use. Visit http://www.dovepress.com/testimonials.php to read real quotes from published authors. 